\title{
Cystic endosalpingiosis of the uterus-a rare entity in disguise
}

\author{
Choudhary $S^{1}$, Agnihotri $P^{2}$, Sehgal $S^{3}$, Jindal $A^{4}$, Yadav $A^{5}$ \\ ${ }^{1}$ Dr. Shweta Choudhary, Resident, ${ }^{2}$ Dr. Priyanka Agnihotri, Resident, ${ }^{3}$ Dr. Sangita Sehgal, Associate Professor, \\ ${ }^{4}$ Dr. Arpita Jindal, Associate Professor, ${ }^{5}$ Dr. Ajay Yadav, Professor and Head, All authors affiliated with Department of \\ Pathology, S.M.S Medical College, Jaipur, Rajasthan, India.
}

Address for Correspondence: Dr. Shweta Choudhary, Girls Hostel, S.M.S Medical College, Jaipur, Rajasthan. E-mail id: drshwetachoudhary@gmail.com

\begin{abstract}
Cystic endosalpingiosis is a non - neoplastic lesion characterised by multiple cysts lined with benign tubal type epithelium. Our case presented as cystic ovarian neoplasm clinically and radiologically. Patient underwent Total abdominal hysterectomy and bilateral salpingo-oophorectomy. Microscopically, the cyst consists of multiple cysts lined by benign tubal type epithelium. A diagnosis of subserosal cystic endosalphingiosis was made. Increasing awareness of this entity would be helpful in making correct diagnosis by pathologists.
\end{abstract}

Key words: Cysts, Endosalpingiosis, Uterus.

\section{Introduction}

Endosalpingiosis is almost always discovered as an incidental finding on microscopic examination without clinical symptoms and is characterized by benign glandular structures with tubal type epithelium [1]. It usually involves the peritoneum, subperitoneal tissues, and retroperitoneal lymph nodes in women [2, 3]. Myometrial endosalpingiosis is rare. We report a rare case of subserosal cystic endosalpingiosis which simulated a cystic ovarian neoplasm clinically and radiologically.

\section{Case Report}

A 50-year-old woman presented with vaginal bleeding off and on since 5 yrs. The ultrasonography showed $7 x 4 \mathrm{~cm}$ multiloculated cyst in the right adnexal region.

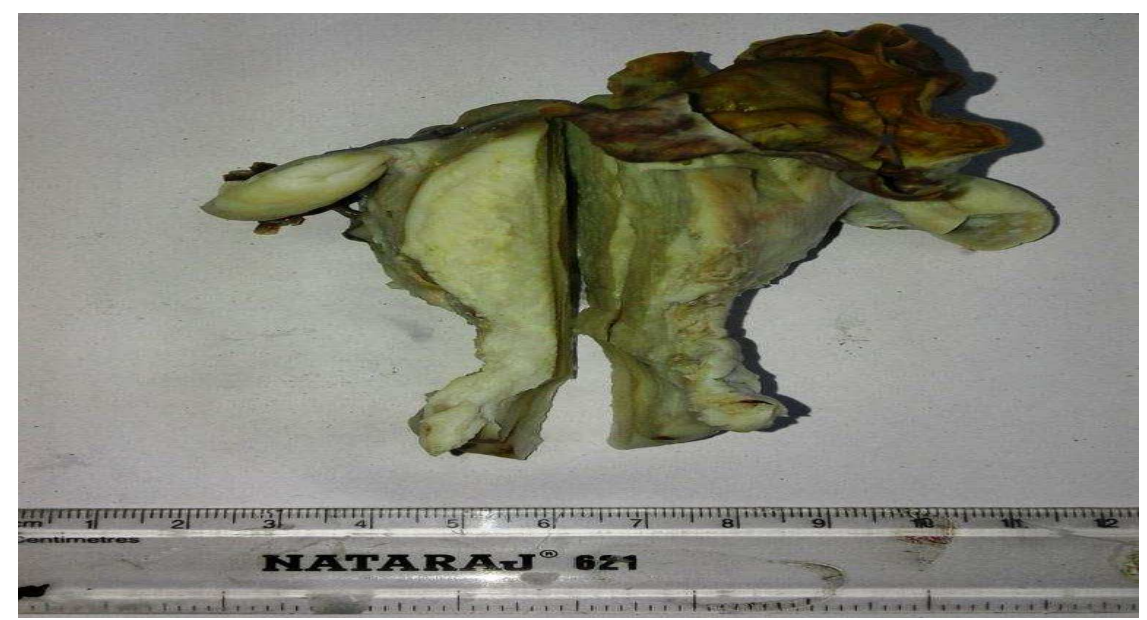

Figure-1: Gross specimen of uterus with bilateral adnexa showing multicystic mass at posterior aspect of fundus

\footnotetext{
Manuscript received $14^{\text {th }}$ June 2016

Reviewed: $26^{\text {th }}$ June 2016

Author Corrected: $12^{\text {th }}$ July 2016

Accepted for Publication $27^{\text {th }}$ July 2016
} 
Pap smear was negative for malignancy. The other laboratory investigations were normal. Total abdominal hysterectomy and bilateral salpingo - oophorectomy were performed. Intraoperatively, subserosal brownish multicystic polypoid mass was seen in the posterior fundus of uterus. The bilateral adnexae were unremarkable. The subsequent course of treatment was uneventful after the operation. Grossly, there was a subserosal cystic polypoid mass in the posterior surface of the fundus of uterus [Fig. 1] measuring $5 \times 4 \mathrm{~cm}$. On the cut surface, mass was multiloculated, solid and cystic showing a smooth inner surface filled with yellowish brown material. Microscopically, the mass consisted of cysts of various size and shape [Fig. 2]. They were lined by a benign-appearing tubal type epithelium. The epithelial lining of the cysts was of the tubular type and was composed of ciliated columnar cells, non-ciliated columnar cells and intercalated peg cells [Fig. 3]. Rest of the uterus, cervix, both adnexae were unremarkable except for adenomyosis in myometrium.

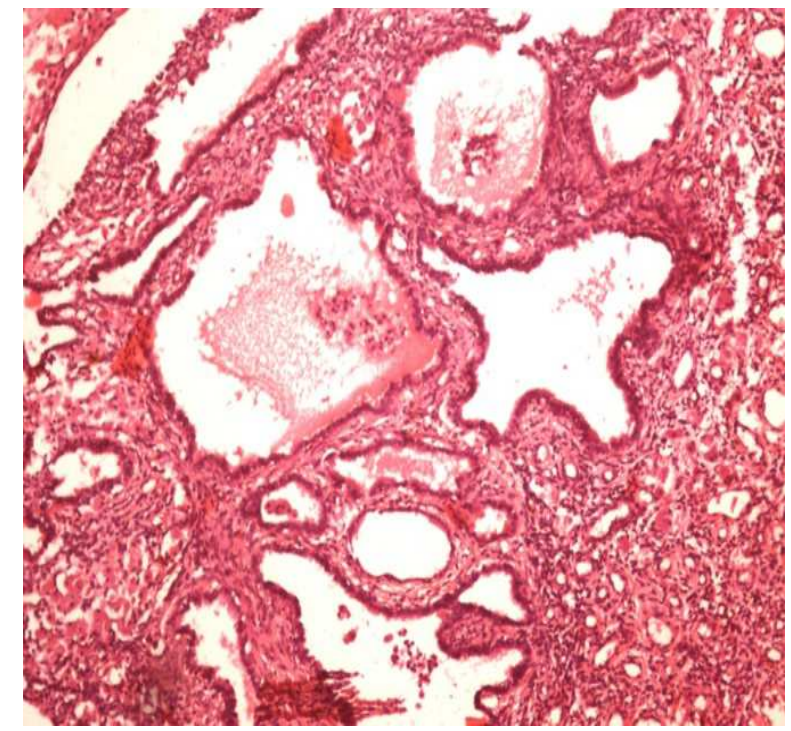

Figure-2: Figure showing multiple cysts of various sizes. (HE 100X)

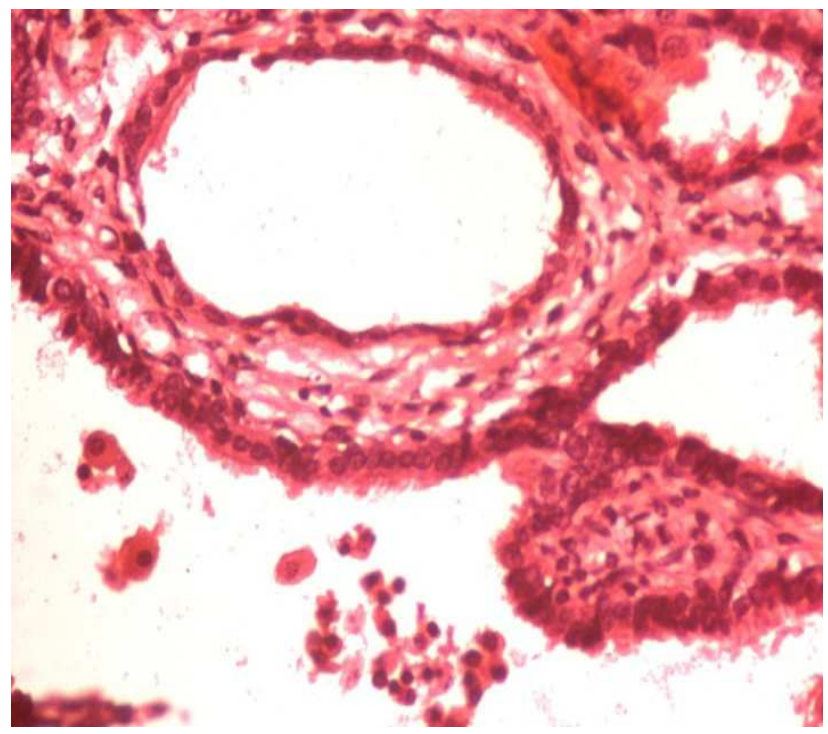

Figure-3: Cysts are lined by ciliated tubal epitheliu (HE 400X)

examinations. Microscopically, however, they are typically lined with a single layer of flat to cuboidal mesothelial cells [4]. The pathogenesis of cystic endosalpingiosis is unknown. The sub-serosal location of the cyst in this case may be explained by the socalled 'secondary Mullerian system theory' [5].

\section{Conclusion}

In conclusion, clinically and radiologically, endosalpingiosis in the uterine horns may simulate a cystic ovarian neoplasm. Awareness of the existence of this rare lesion will prevent an incorrect diagnosis by clinician and pathologist.

Funding: Nil, Conflict of interest: None initiated, Permission from IRB: Yes

\section{References}

1. Shim SH, Kim HS, Jo M, Chang SH, Kwak JE. Florid cystic endosalpingiosis of the uterus: A case report. Korean J of Pathol. 2008;42:189-91. 
2. McCluggage WG, Clements WD. Endosalpingiosis of the colon and appendix. Histopathology. 2001 Dec;39(6):645-6.

3. Papavramidis TS, Sapalidis K, Michalopoulos N, Karayannopoulou G, Cheva A, Papavramidis ST. Umbilical endosalpingiosis: a case report. J Med Case Rep. 2010 Aug 24;4:287.doi:10.1186/1752-1947-4-287.
4. Clement PB. Disease of the peritoneum. In: Kurman RJ ed. Blaustein's Pathology of the Female Genital Tract. 5th ed. New York:Springer 2002; 735-6.

5. Lauchlan SC. The secondary Müllerian system. Obstet Gynecol Surv. 1972 Mar;27(3):133-46.

\section{How to cite this article?}

Choudhary S, Agnihotri P, Sehgal S, Jindal A, Yadav A. Cystic endosalpingiosis of the uterus-a rare entity in disguise. Int J Med Res Rev 2016;4(8):1315-1317.doi:10.17511/ijmrr.2016.108.06. 